\title{
Environmental Impact Assessment Initiated to Mitigate Pollutions from Industries
}

\author{
Shadika Haque Monia \\ Lecturer of Law, Britannia University, Bangladesh
}

\begin{abstract}
Industrial pollution is a Buzzword of the present world. At the same time, there needs industrial development along with the mitigation of pollution, but in practice, industries are increasing with polluters although protection of pollution is lagging. The conservation of natural wealth is growing through various processes without thinking about the future. As an overpopulated country, a large number of industries have been contributing to enrich the economy of Bangladesh. In addition to there is no specific legal mechanism in the country to control industrial pollution which causes danger for the environment. The paper endeavors to find out the present legal instruments regarding environmental pollution caused by industries in Bangladesh, whether these are sufficient to prevent such pollution or not. Therefore, there is no specific legislation under IEL to mitigate industrial pollutions The research will contribute to the courtier's policymaking in the field of environmental protection, very few research has done in this area. As there is no specific legislation dealing with industrial pollutions, the Article tries to facilitate the need for specific legislation or mechanism on this matter by mentioning critics of existing legislations and found that, in absence of specific legislation the country is facing environmental threats every day. The data is analyzed with qualitative methods, both primary and secondary data is analyzed for the same. The research is done with doctrinal based analytical research.
\end{abstract}

Keywords: Industries, pollution, Environment, Protection, Bangladesh, Assessment

\section{This is an open access article under the CC-BY-NC license.}

\section{INTRODUCTION}

Predominantly, Bangladesh is an agriculture-based country. Environmental pollution was never even found as a factor of anxiety in the past. With the initiation of different types of industries, it seems through various research and survey that, the ecological imbalance is being caused gradually due to the escaping of various industrial wastes into the natural environment such as soil, air, and water. It has also been initiated that the severity of pollution produced by the different factories and industries depending on their nature, present environment, used resources, chemicals, the exercise of production, and expulsion of different types of pollutants to the natural environment. Industrial pollution has become an important part of every day's newspaper. But in the absence of specific legal mechanisms, the problem of Environmental pollution causes by industries is now beyond under control. Possible controlling mechanisms have been initiated but there has not found any solution till now. To this extent, not only the government of Bangladesh but also non-governmental organizations are working together. But in the absence of specific legislation or mechanism, the country is unable to come out form this problem.

Environmental pollution is treated as one of the severe threats for human health and the economy of Bangladesh, different types of waterborne diseases, arsenic poisoning is caused by industrial pollutions. Dhaka, the capital city of Bangladesh has been suffering from severe environmental pollution. Per capita pollution from Buriganga and other rivers from Dhaka is 25gBOD/capita/day. Therefore, 
nearly $0.3 \mathrm{mg} /$ liter/year dissolved oxygen is declining in Buriganga. Unplanned urbanization with industrialization is largely responsible for the same. Improper waste management is also another important cause of environmental pollution. In the absence of effective pollution control mechanisms and strike enforcement, the problem is yet to solve. The iron and steel industry in Bangladesh can be listed in the largest polluters of air and water. Also, fertilizer industries affect aquatic life and contaminate rivers or sea. Various poisonous chemical such as ammonia affects the land area and fertility. As the government is willing to promote industry for its economy, precautionary measures should also be taken to control pollutions as well.

\section{LITERATURE REVIEW}

To supply, a huge amount of food and employment the government has to promote industries as Bangladesh is an overpopulated country, the population rate is growing steadily than the total amount of land. Degradation of forest and urbanization have some negative effect on the environment as well. Land areas of various divisions and land areas of Chittagong Hill Tracks areas have decreased as well. The productivity of land has been losing day by day due to water erosion and the declining fertility of the soil. In the absence of a specific waste management system industrial waste is treated as the most common cause of environmental pollution. Industries have established here and there but without any certain manner to dispose of their waste most of the cases nearby river and channels are the ways of throwing waste materials and garbage. For the reason of industrial pollutions, the country is losing its biodiversity gradually. Ecological imbalances have been increased. Not only factories and industries but there are also eight Export Processing Zones in Bangladesh, these EPZ have great influence in the economy, although they dispose of a large number of waste materials per day. Surface water becomes contaminated with a huge amount of waste materials as well. (Gain, 1998)

Apart from these, cottage industries in Dhaka are another culprit of industrial pollution in Bangladesh. There is no specific standard pattern of waste management in some selected cottage industries in Dhaka, especially in the old city. Almost 4-22 kg of solid waste materials are being dumped by these cottage industries, liquid waste materials are disposed of from textile and dyeing industries, the amount is between $200-400 \mathrm{Kg}$ per day. Plastic and metal factories are greatly responsible to create huge amounts of noise or sound pollution in the environment as well. Health problems are also created from rubber, battery, soap, and chemical industries. Polythene and plastic industries are mentionable to this extent as well. Also, a large amount of toxic chemicals contaminates groundwater every day. Leather export processing industries in Hazaribagh at Dhaka were greatly responsible for disposing of chemicals on the surface. (Pandey, S. N. 1989)

As a part of solid waste most of the cases, chemicals, and waste materials disposed of, the pulp paper and cement factories emit a large number of chemicals to the environment. Air pollution has a deleterious impact on human life, especially for children. Most of the factories and industries are situated in urban areas. Emission of harmful gases in the air is the main source of air pollution and in the rural areas brick kilns, burning wood is the main polluters. Generally, the soil of Bangladesh is not only fertile but productive too. The quality of soil as well as productivity is going to reduce for NPK as fertilizer and emissions of waste materials. As a consequence of soil pollution, soil quality has been spoiled. Apart from urban and rural areas land quality of Chittagong Hill track areas has been reducing. (Khisa,1997)

National Board of Revenue of Bangladesh (NBR) has listed 2,500 industries as polluters among them, almost 1,200 industries are situated in Dhaka city. The total amount of groundwater has been 
reducing gradually in the last two decades in Dhaka, the capital of Bangladesh although about $72 \%$ of water supply in Dhaka city largely depends on groundwater. To meet such a huge demand for water, the water level is decreasing by 2-3 meters yearly. If these situations continue groundwater levels will drop between 110 to 115 meters by 2050. Methane gas emissions from the garments industries are responsible for global warming as well. Chemicals used in garments contaminate groundwater. Waste and garbage from industries not only pollute the environment but also increase fuel consumption. The average fuel efficiency of most of the factories is only 20-25 percent. World Bank initiated an industrial pollution projection system (IPPS), which is capable to make reasonable projections for all pollutants. The proper initiatives from the government, administrative authorities, and industries are not working properly due to proper coordination which hurts the environment. (Hettige,et.al.1994)

The global garments industry has a huge market and Bangladesh is also the second-largest garments exporter country of the world. However, this garment sector is one of the remarkable sources of pollutants in the world. The garments industries are responsible to dispose of 20 percent of polluted water and 10 percent of carbon dioxide over the world. from garments industries where only $15 \%$ of water can be reused in this sector, thus the rest of the waste materials return to the environment. (Kapur, S.M, 2005)

Therefore, very little research has been done in the field of environmental pollutions caused by industries in Bangladesh. Most of the previous research has discussed the causes and impacts of industrial pollutions rather than discussing a strategy to mitigate.

\section{RESEARCH METHOD}

The research will be a doctrinal based analytical study of the respective subject area. It would be a discussion-based work with the available sources of law relating to the subject matter. It would be based on not only the primary sources but also secondary sources. The domestic legislation as well as international legal instruments concerned with the issue include primary sources, the relevant practice of the states and organs of the United Nations including the critical examination of the decision of different courts and tribunals. The secondary sources include books, articles, and reviews of case laws on this subject matter. Journal Articles, Editorials, and Digital sources are explored and utilized for this purpose too.

\section{RESEARCH QUESTION}

1. What are the impacts of Industrial pollution in Bangladesh?

2. What is the protection mechanism in the absence of specific legislation?

3. What are the gapes of the present legal framework to mitigate industrial pollution?

In the first part of the Article, it tries to assess the first research question, about the historical background of industrial pollution in Bangladesh, classification, and ramifications of industrial pollution..

In the next phase of paper, the Legal framework on International Environmental Law discusses the second research question in the light of domestic and international instruments regarding industrial pollutions. In the following part, the third research question is discussed, the discussion includes contemporary state practice of Bangladesh, legislation, protection of Environment without a specific legal mechanism, and gapes of the present legal framework. Finally, the paper recommends a few possible solutions to control industrial pollution for the protection of environmental pollutions analyze the entire study and will conclude with the understanding of the issue as findings of the research gap. 


\section{RESULT AND DISCUSSION}

Industrial Pollution in Bangladdesh

The most common definition of environmental pollution can be the introduction of various harmful pollutants into a particular environment, make this environment insalubrious to live in. The well-known pollutants are usually chemicals, garbage, and wastewater. "Industries dispose of waste materials such as gaseous, liquid, or solid waste materials. These poisonous substances usually throw into the atmosphere. Industrial pollution is one of the processes of environmental pollution by the emission of industrial waste into the environment.

"Industrial pollution is the release of wastes and pollutants generated by industrial activities into the natural environments including air, water, and land, linked to the degradation of the natural environment, impacts the environment in multiple ways and has grave consequences on human lives and health. (A. Kiss, D. Shelton, p.8-9).

By late 1990, almost sixty industrial lands along with Export Processing Zone (EPZ) has established. Notably, the growth of Readymade garments (RMG) is mentionable in the same sector as well. On the pint of pollution, major pollutants are various factories including leather, dyeing, pulp, ship braking industries. Mineral resource-based industries and industries with non- renewable private reserve-based industries such as limestone, hard rock, gravel, grass, sand, and various types of clays. In this classification, most major polluters are the cement and fertilizer factories. Therefore, the industries based on imported resources including textiles, pharmaceuticals, plastics, petroleum, and metal works. Most of these are originated to be exceedingly polluting. From a few years' policymakers have been under the consideration that, as Bangladesh is one of the less developed countries in the world, nowadays pollution has become an important issue to be concerned about. Therefore, different studies commenced in the last decade have scattered such beliefs.

Types of Environmental pollution causes by Industries:

Industries are significantly responsible for environmental pollutions. Environmental pollutions created different ways along with industrial issues such as:

Air pollution caused by Industries in Bangladesh is a common phenomenon. A large number of industries dispose of gaseous and chemicals into the air, which is highly responsive to cause harm for human beings as well as for the other living organism. The atmosphere also depends on a dynamic wave and the natural air circulation system mainly supports life on the planet on this Earth. Stratospheric ozone depletion due to air pollution has been initiated as a great threat to human health. Various poisonous elements such as Sulpher Di Oxide, Carbon Di Oxide, Nitrogen Di Oxide, chloro-fluoro-carbon get radiated from various industries and amalgamate to the atmosphere and creates environmental disaster. Industries of Bangladesh are significantly responsible for air pollution through emitting smoke, throwing wastage which produces odor. Therefore, Brick kilns, fertilizer factories sugar and pulp mills, jute mills, textile and spinning mills, garments, chemicals, and pharmaceutical mills, cement mills, are largely responsible for air pollution in the country. Sever dust and chemicals, smoke, steam create a foggy and smoky environment. The factories such as tannery emit hydrogen sulfide, ammonia, chlorine to the air, and creates various health problems.

In terms of collapsing river India, Bangladesh and Nepal are in the top listed countries of South Asia. Almost eighty percent of wastewater from urban and industrial areas is being discharged into the natural water bodies without refining. As a result, pollution with chemicals is increasing especially in the revers and thus river water is getting contaminated day by day. 
Industrial wastage and garbage pollute both surface and groundwater sources. A study made by World Bank said that 1.5 million cubic meters wastewater is thrown by 7,0000 industrial units per day by in the four main revers near Dhaka city and 0.5 million cubic meters from other sources of the same areas. Toxic elements such as cadmium and chromium and other elements like mercury carried by the industrial waste are also mixed into the groundwater; create a significant threat to public health. The emission of domestic and urban sewage, wastage from agricultural units create water pollution. Presently, waste materials of various industries are treated as the largest source of water pollution in Bangladesh. Industrial waste such as acids, alkalis, chemicals from dyeing industries, toxic metals, pesticides, and radioactive materials can easily be mixed into the water bodies. A large number of pollutants like ammonium chloride, cyanide and zinc, mercury from petrochemical industry, polythene and plastics industry, fuel industry, mineral oil refining industry get mixed with the water bodies.

As a consequence of urbanization, and industrialization freshwater is rapidly declining. To circulate pure drinking water for the overgrowing population in the country, predominantly water pollution should be controlled.

Over growing, industries, and waste materials from these destroy the fertility of the land. and thus productivity and quality of the soil have been reducing accordingly. A lot of solid wastes such as safe and rejected chemicals like calcium carbonate, magnesium sulfate along with various poisonous elements are also blameworthy for the same. In the absence of a specific waste management system, most of the industries of the country dispose of various waste materials such as plastic, wooden materials, chemicals to the land. To provide foods for a large population, fertilizer, and pesticide use in the land, which are also accountable to reduce the productivity of the land. Pollution of groundwater is also caused by soil pollution. Most of the revers of the country become polluted by industrial waste, agricultural land nearby the rivers also contaminated by the river water. Out of 83 percent of the cultivable land, almost 3 percent is an organic matter as a consequence of using chemical and fertilizer in the land.

Instruments relating to various processes of functioning created by the industries are treated as the major sources of sound pollution in Bangladesh. Industries in the urban areas added extra panic for the same. Most of the industries create sounds which cross the boundary of hearing for the people. According to the World Health Organization (WHO, in the residential area sound range must be up to 65 decibels in the day time and the rage must be up to 45 decibels in the night, in commercial areas 75 decibels during the day and 55 decibels at night; In industrial areas, the noise level should be between 75 decibels during the day and 65 decibels at night. The sound or noise level in the hospital zone should have to be in 50 decibels, if the level becomes increased it is determined as pollution. Also, only 60 decibels sound is responsible to create temporary deafness and 100 decibels sound can cause complete deafness for the human being.

Most of the industrial is situated near to the major roadside or cities. Not only in the daytime but also the night, sound pollution hamper regular activities of the society. The workers are the direct sufferer of sound pollution of the industries, the nearby residents, school children, medical personnel are also significantly affected by noise pollutions caused by industries.

Industrial pollution is not only a threat to human health but also for the living organism, therefore, economic development is also being threatening for the same cause. Long term effects such as asthma and bronchitis are caused by environmental pollution. The nervous and reproductive system along with the affecting kidney and liver including liver cancer. Industrial emissions are also the direct cause of different waterborne diseases such as damage to health. It can be responsible for Melanesia, kurtosis, and conjunctivitis. Not only mental illness but also physical illness have been increasing among people as 
a result of sound pollution. Different types of waterborne diseases are caused by drinking polluted water. Environmental pollutions have created the causes of heart attack, peptic ulcer, high blood pressure, deafness, headache, skin diseases, and indigestion.

As a consequence of urbanization and industrialization, the environment of the country is facing severe damages, the water level is falling at an alarming rate. Various water bodies such as canals and rivers are being polluted. Human health especially, poor people and children are in great danger of environmental pollutions. The water and soil of major cities of the country have also been found with a poisonous substance such as arsenic, chromium, pesticide, and sulfur dioxide. To control noise pollution, the vehicles causing noise pollution should be identified and need to take proper actions against them. To control air pollution, emission of gases need to protect. The tree plantation campaign should be implemented strictly.

Legal framework on International Environmental Law

In London, at 1306, Edward adopted an ordinance to prohibit the use of coal in open furnaces, which is the oldest measures in the field of Environmental pollution . "Bad-smelling and disgusting smoke" was forbidden by Charles IV forbade in the 14th century, at Paris. With the inauguration of different types of industries as well as the process of industrialization, protecting measures for the environment became more specific and urgent.

The development of existing international environmental law can be classified into two critical phases such as a) the first UN Conference on Environment held in 1992 on sustainable development; at Stockholm b) Rio Conference in 1992 on sustainable development. The Stockholm conference was settled with adopting three documents such as a Resolution relating to financial agreements and institutional agreements, a Declaration of principles with a Plan of Action. These reports provide a significant result of the conference as well as may be determined by international environmental law as they define lots of policies along with the 26 principles regarding environmental protection with human rights. Rio Conference corroborated more the principles pronounced in Stockholm.

Principle 3 of Rio declarations stated that:

"The right to development must be pursued to meet the equitable development and environmental development for the present and future generation. Its principal gave importance to the global environment, for this reason, the Climate Convention was significantly important. One of the most significant concerns may be the obligation of signatories to publish greenhouse gas emission data."

Moreover; the only voluntary agreement is there to control the growth of $\mathrm{CO} 2$ emissions. Three documents were adopted in Rio conferences such as Declaration on Environment and Sustainable Development which is followed by the principles of Stockholm; some other rules on use and protection of Forests which are non-binding along with agenda 21 , programmatic document with a non-binding effect aims to established programs, initiatives, and priorities to protect the environment in the 21st century.

The watercourse convention was about the uses of international watercourses and to take measures for protecting, preserving the better management relating to the uses of waterways and their water. Like any other national or domestic environmental laws or international laws, the International Environmental law is needed to encourage systemic changes to protect the environment from industrial pollution. Systemic regulatory and potential approaches should be initiated to address environmental pollution caused by industries. There must be a particular convention regarding environmental pollutions caused by Industries; there must be consumption and protection practice. There are some major reasons behind this such as: 
During the 2oth century, especially in the first half, the problems relating to environmental pollution become an issue of international tension, so the international community solved the problem locally or by domestic laws. Technological development and damage were absent caused by a state to others were not existed as so strong. So, with the development of technological inventions and industrial developments, the need for special conventions relating to preventing industrial pollutions is getting importance.

Along with the domestic laws, there must be provided incentives to a wide acceptance range of pollution prevention techniques to protect the environment. As it is an age of Globalization, economic development along with the free trade agreement, multilateral trade agreements, and the world has become a global village. For this reason, the demand is increasing for specific provisions relating to the protection of industrial pollutions, as the issue is getting more privileged day by day, undoubtedly.

Most of the time the protection of the Environment becomes a matter of national interest to the countries along with the less interest of the International dimension. International Environmental Law is an undeniable part to regulate soft law which is not obligatory and declarative too. In the absence of a particular right to the real environment, and it is tough to deal with the existing laws under IEL. Another important thing is that the department of environmental law is profoundly influenced by politics although, the essential priorities about the "polluter pay principle' 'and it's application, strengthened the remedies over each polluters relating to the components of the environment.

Therefore, sometimes it becomes tough to solve the environmental pollutions caused by the industries only by a state unilaterally. In this regard, international cooperation between countries can be very helpful. And these legislations can be applied without any option the issues such as global warming, biodiversity, and other environmental pollutions. .

Bangladesh has ratified so many international instruments regarding environmental pollutions; most of these conventions have particular issues and preambles although there is no specific convention relating to industrial pollutions. The environment has to protect from industrial pollutions with its own domestic rules as there are no specific conventions relating to industrial pollutions. But sometimes it becomes difficult as there is no particular convention under IEL relating to the protection of industrial pollutions.

Legal Framework on laws of Bangladesh

There is the absence of direct constitutional provisions to protect the environment, so the judiciary adopted the liberal and harmonious interpretation of some fundamental rights to provide environmental protection. Presently in Bangladesh, several environmental protection actions are dealt with under the provision on the right to life under the constitution of Bangladesh. The writ procedure is more preferable over the current suit as it is speedy, comparatively inexpensive, and provides direct entrance to the highest courts of the country. It was a court judgment, and the court decided: There is no direct provision regarding the right to the environment under the Constitution of Bangladesh. As a result of high demand as well as the movement of civil society along with the environmentalists the 15th amendment of the constitution of Bangladesh, provision for 'conservation' and development of environment' has been inserted in the part of the fundamental principle of state policy ensured by the Constitution of Bangladesh. Thus, it does not recognize the right to the safe environment of the individuals, and industrial pollutions are far behind from this provision. It is only asserted as one of the fundamental principles of state policies, can be used as a guideline to interpreting the Constitution as well as the other laws of Bangladesh, and shall be applied to make of laws. 
Judicial recognition to protect the environment was first recorded by the High Court through the case of Dr. Mohiuddin Farooque Vs. Bangladesh and others where challenged nuisance during the election campaign. The judiciary inclined the case on the assertion from the Attorney General to take measures against damaging public and private property in the name of the election campaign. 1994, public interest litigation was introduced before the Supreme Court to allocate air and noise pollution. In that case, the legal recognition for protecting the environment was recorded first time by the High Court of Bangladesh through a case that was challenged nuisance during the campaign of an election.

Existing legislations

National Environmental Policy (NEP) was adopted in 1992; the main aim of this policy was to provide protection and sustainable management of the environment. The objectives include maintaining the ecological balance and ensuring development along with the safety and development of the environment.

In 1995, the Bangladesh Environmental Conservation Act was enacted in 1995 and Environmental Conservation rules in 1997, without any doubt the most significant judicial documents. The Act is being implemented by the Department of Environment (DoE) implements. DoE is also regulated by a Director General (DG). DoE has the authority to visit the project, investigate, assess, test, and snatch, industrial plant if DoE thinks that there can be found anything which is harmful to the environment and can be the cause of pollutions. Therefore, DoE has the right to collect any symbol to analyze the presence of harmful components on it. The DoE can recruit public hearings only when an application is submitted by an individual or group of people, who are affected by pollution. After coming into force of the 1995 Acct, Industries and industrial units must have to gain an "Environmental Clearance" certificate from the DoE. There is an appeal procedure if anyone fails to get clearance. If anyone fails to obey the provisions of the Act, the punishment will be maximum 10 years imprisonment or a maximum fine of Tk.10,00,000 (Ten Lakhs) or both. The term for Environmental Clearance is also fixed according to their nature and at the expiry of the period of the certificate, one has to apply to renew before 30 days of expiry.

The Environment Court recognized under this Act of The Environmental Court Act 2010, is important to ensure the conservation of the environment. The provisions are, such as establishing the court of the Special Magistrate, providing the Jurisdiction of the Court of Special Magistrate, the Jurisdictional procedure of environment court and the court of the Special Magistrate, authorities and, the provision regarding mediation, the appeal process and environment appellate court and power of rulemaking. The national environmental quality standards for air, water, industrial effluents, emission, noise, vehicular exhaust, etc along with other provisions are proclaimed in these rules. In 1977 standards for air quality, standards for the motor vehicle, the standards to reduce black smoke emissions by boat/ship/vessel and the standards to reduce industrial stack emissions have been to set the reporting criteria for activities, processes along better management. For Island surface water, general industry discharge standards are given.

Emissions standard for each of the limits is provided for classified industries, including fertilizer factories; integrated textile mill and large processing units; pulp and paper companies; cement plants; industrial boilers; nitric acid plants; distilleries; sugar production; leather tanneries; processing food and oil refineries. However, several parameters are not determined in the Rules as these are toxic such as copper, cobalt, and aluminum is not specified in the waste quality standards. The industries cover significant water sector interventions are provided EIA guidelines such as flood control embankments and banks and roads, and bridges. 
Bangladesh has a large number of industries, which fill-up the domestic needs and export to other countries also; a large number of people are engaged in this sector although there are no particular laws in this regard. This is because; it creates difficulties to prevent environmental pollutions with the existing rules of Bangladesh. In Bangladesh, there are so many legislations specifically deal with environmental pollutions, but no particular law for addressing Industrial pollution. For this reason, issues relating to industrial pollutions deal with the existing legislation such as Environmental conservation act 1995, which provides maintenance, Improvement of the environment, control, and mitigations of Environment. Article 15(A) of this stated that DoE could sue against the offender if anyone commits any activities harmful to the ecosystem. But, in reality, most of the time DoE fails to prevent dangerous acts for ecology on its own. Therefore, it is accepted that no realistic expansion of the DoE in the future it will be tough to cope with the problems. Human resources are scarce in DoE, although the DoE has to monitor any other environmental issues along with the industrial pollutions

There is the Environmental Courts Act 2010, where the provisions are relating to establishing Special Magistrate court along with the powers of appeal, medications, and so on. But most of the time it becomes desperate to punish an established industrialized, as there is political instability in Bangladesh. Although there is a process of taking environmental clearance before starting industries, most of the time they got clearance very easily with political power or illegally. Thus they misuse the meaning of Environmental clearance. Moreover, another important thing is that although there are legislative privations to mitigate environmental pollutions, proper monitoring is absent, there needs a better surveillance system in every district especially where there are industries and pollutions are increasing. As industry and industrial pollutions are growing rapidly, so there needs specific legislation along with the detailed procedures for protecting the environment from industrial pollution with better implementations.

\section{CONCLUSION}

The conclusion, recommendation, and implications

The environmental conservation should be the human rights-based approach. The principles of international conventions and treaties having a bearing on the protection of the environment ratified and signed by Bangladesh can take predominant measures to control environmental pollution in Bangladesh. The National Human Rights Commission (NHRC), the government can make awareness to the people organizing the seminar in different aspects of the conservation of the environment to be conscious about the right to environment. 'Mobile Court' can be delegated some powers to implement the Conservation of Environment relating laws. The Law Commission can take an important role in identifying lacuna of existing legislation, promoting environmental education, and organizing the national seminar for awareness building towards conservation of the environment. The necessary amendment and enactments of laws to protect industrial pollutions should be initiated. Particular environmental Courts can be established under the control of the judiciary, increases their transparency and accountability as well.

Nowadays, environmental issues have become one of the major concerns for the greater impact on public health and environmental conservation of Bangladesh. Air, water, and sound pollution are the main elements of environmental pollution in the country. To ensure the right to environment, some steps should be taken. Therefore, industries must be given some criteria to fulfill before initiating their production units. A proper waste management system is also necessary for the same. In the absence of a specific legal framework, the problem is getting severe day by day. In addition to several loopholes of 
present legislation encourages polluters in this regard. Both governmental and non-governmental strategies are quite unsuccessful in the point of mitigating environmental pollutions. To this extent, a specific legal framework along with a stick enforcing mechanism is required. Finally, public awareness should be increased through a public campaign across the country to change human behavior and living style.

\section{REFERENCES}

Alam, G. J. (2009). Environmental pollution of Bangladesh-it's effect and control. Pulp and Paper, 51(13.17).

Alam, G. J. (2009). Environmental pollution of Bangladesh-it's effect and control. Pulp and Paper, 51(13.17).

Alam, M. G. M., Allinson, G., Stagnitti, F., Tanaka, A., \& Westbrooke, M. (2002). Arsenic contamination in Bangladesh groundwater: a major environmental and social disaster. International Journal of Environmental Health Research, 12(3), 235-253.

Annual Report by Department of Environment, Ministry of Bangladesh

Annual report by DOE

Annual Report By world health organization-2015 Available in <http://www.who.int/topics/en/>n(Last accessed on 25 March 2019)

Arefin, M. A., \& Mallik, A. (2018). Sources and causes of water pollution in Bangladesh: A technical overview. Bibechana, 15, 97-112.

Azad, E. (2014). Environmental pollution in Bangladesh: the need for a legal overhaul. Bangladesh Law Association Journal, 1(1).

Bearden, D. M. (Ed.). (2011). Environmental laws: summaries of major statutes administered by the environmental protection agency. DIANE Publishing.

Blackman Jr, W. C. (2016). Basic hazardous waste management. CRC press.

Brundtland, G. H. (1985). World commission on environment and development. Environmental policy and law, 14(1), 26-30..

Environmental impact Assessment initiated to mitigate pollutions from industries.

Giorgetta, S. (2002). The Right to a Healthy Environment, Human Rights, and Sustainable Development. International Environmental Agreements, 2(2), 171-192.

Government of the People's republic of Bangladesh, 1995, The Bangladesh Environment Conservation Act, 1995 (Section-4)

Government of the People's republic of Bangladesh, 1995, The Bangladesh Environment Conservation Act,

Haque, N. (2017). Exploratory analysis of fines for water pollution in Bangladesh. Water Resources and Industry, 18, 1-8.

Haque, N. (2017). Exploratory analysis of fines for water pollution in Bangladesh. Water Resources and Industry, 18, 1-8.

Hill, M. K. (2010). Understanding environmental pollution. Cambridge University Press.

Islam, M. S. (2015). Implementation of policy to control industrial pollution in Bangladesh: major drawbacks. In Public Administration and Policy in the Middle East (pp. 297-317). Springer, New York, NY. 
Karim, M., Matsui, H., Ohno, T., \& Hoque, S. (1997). The current state of traffic pollution in Bangladesh and metropolitan Dhaka (No. CONF-970677-). Air and Waste Management Association, Pittsburgh, PA (United States).

Karn, S. K., \& Harada, H. (2001). Surface water pollution in three urban territories of Nepal, India, and Bangladesh. Environmental Management, 28(4), 483-496.

Karn, S. K., \& Harada, H. (2001). Surface water pollution in three urban territories of Nepal, India, and Bangladesh. Environmental Management, 28(4), 483-496

Khopkar, S. M. (2007). Environmental pollution monitoring and control. New Age International.

Latif, S. A., Hossain, S. M., Uddin, M. S., Hafiz, M. A., Islam, M. A., \& Mubin, M. S. H. (2008, November). Studies on environmental pollution in Bangladesh using a reactor-based neutron activation analysis technique. In International Conference on Research Reactors: Safe Management and Effective Utilization, Citeseer.

Liaquat A. Siddiqui, 'The Legal Status of the Emerging Principles of International Environmental Law', The Dhaka University Studies, Vol.9, p, 45,1998

Marcoux, R. M., \& Vogenberg, F. R. (2015). Hazardous waste compliance in health care settings. Pharmacy and Therapeutics, 40(2), 115.

Md, S. J., Md, P. S., Uddin, A. M. M. B., Md, H. M., \& Tanmay, M. H. (2016). Macrobenthic community structure-an approach to assess coastal water pollution in Bangladesh. Fish Aquac J, 7(157), 2.

Mihiuddin Farooque, 2004, 'Selected Writings of MOHIUDDIN FAROOQUE' BELA, Dhaka, p. 141.

Pathak, R. S. (1992). The human rights system as a conceptual framework for environmental law. in, 205243.

Pitt, M. M., Rosenzweig, M. R., \& Hassan, M. (2005). Sharing the burden of disease: gender, the household division of labor, and the health effects of indoor air pollution. CID Working Paper Series.

Preamble of the Rio Declaration, 1992

Principle 3 of Rio declarations 1992

Rao, C. S. (2007). Environmental pollution control engineering. New Age International.

Rasul, M. G., Faisal, I., \& Khan, M. M. K. (2006). Environmental pollution generated from process industries in Bangladesh. International journal of environment and pollution, 28(1-2), 144-161

Rieuwerts, J. (2017). The elements of environmental pollution. Routledge.

The Constitution of the People's Republic of Bangladesh of the constitution of the people's republic of Bangladesh,30jun,2011

The Convention on Biological diversity1992

The Environment Conservation Act, 1995, has repealed the 1977 Ordinance.

The environmental court Act of Bangladesh-2010, Ministry of Law of Bangladesh, section 18

The Rio Declaration on Environment and Development, often shortened to Rio Declaration, was a short document produced at the 1992 United Nations "Conference on Environment and Development" (UNCED), informally known as the Earth Summit

The United Nations Conference on the Human Environment was held in Stockholm, Sweden from June 5-16 in 1972

World banks report on Industrial pollutions, Available in http://www.worldbank.org/?cid=ECR_GA_HPlaunch_searchad_EN_EXTP\&gclid=CObupcP1_dM CFc8TaAodqVgCLw,

Zakaria, N. G., Rashid, K., \& Khaled, M. I. (2017). Environmental Pollution in Bangladesh by Inland Tanker Operation. Procedia Engineering, 194, 330-336. 